\title{
Studies on the Tensile Properties of Spherical Amalgam
}

\author{
by \\ Kazuo NAGAI* and Masayoshi OHASHI* \\ Research Collaborators \\ K. MIHARA, I. MAKI, M. KAWAMOTO, Y. TASHIRO, \\ K. SETO, F. ARAI, J. YAMAGUCHI, Y. NAGATA, \\ Y. FUJIMOTO and H. OYA
}

1. Introduction

2. Materials and Method

2.1 Materials

2.2 Determination of specimen size

2.3 Preparation of test specimens

2.4 Testing apparatus

2.5 Testing method

3. Results

3.1 Tensile strength

3.2 Elongation

3.3 Stress-strain curve and modulus of elasticity

4. Discussion

5. Conclusions

References

\section{Introduction}

Ever since the adoption by American Dental Association in 1929 of test specification of dental amalgam alloys as A. D. A. specification No. 1[1], many studies have been successively carried out on the physical, chemical, mechanical and clinical properties as manipulative variable affecting clinical results of this widely used restorative material. Amalgam has come to account for nearly $75 \%$ usage among various restorative materials by the dental clinicians of today [2], attesting to its importance and ease in handling.

Despite this wide usage, however, many reports are published on the failure cases of amalgam restorations by such investigators as Healey and Phillips [3], SEINO [4], Fusayama et al. [5], Saijo [6], Habu et al. [7], and Wilson and Ryge [8].

Although it is generally accepted that most of the failures are attributed to inadequate cavity preparation and unsatisfactory amalgam manipulation, it was pointed out by NAGAI et al. [9] that the failure should be also sought in the innate characteristics of dental amalgam itself.

* 永井 一夫, 大橋 正敬：Dept. of Dental Materials, Nihon Univ. School of Dentistry, Tokyo. 
After nearly 100 years' history of amalgam made from shavings of an alloy ingot, the United States succeeded in manufacturing spherical-particled alloy in 1961[10]. DEMAREE and TAYLOR [11] published their basic study on this new alloy the following year and it was followed by KORAN and ASGAR [12] in 1965 and successively by EDEN and WATERSTRAT [13] and WING and RYge [14].

In Japan, on the other hand, NAGAI, OHASHI, MrYAZU and their collaborators [9] published their comprehensive study on a spherical amalgam, the first of its kind to be commercially sold in the world, in 1966 and it was also in this study that a NON condensing apparatus was constructed and introduced for the specific condensation of spherical amalgam. NAGAI, OHASHI et al. $[15,16,17,18]$ continued their efforts into basic studies of this new dental restorative material and improved on the previous NON condensing apparatus. The improved apparatus was termed "new NON condensing apparatus" and its adoption for the future testing of amalgam was strongly recommended at a dental international conference. In its wake, there followed detailed studies of setting expansion, marginal strength, corrosive tendency, etc., of the Japanesemade spherical amalgam. All of these studies have brought to light pronounced advantages of spherical amalgam over conventional amalgams. Parts of their findings were used as a basis for their recommendation for incorporating in amalgam specification test formulated by F. D. I.

As clinical failures of the amalgam restorations, HEALEy and PHILLIPS [3] gave $26.2 \%$ fracture of all the failures while SEINO [4] gave as many as $32.3 \%$ fracture out of the total cases examined. It is generally admitted that although the restorations chiefly receive the compressive stress during mastication, they are also subjected to shearing and tensile stresses.

According to SkINNER [19], the compressive strength of a satisfactory amalgam probably should be at least 3,200 kilograms per square centimeter $(45,000$ pounds per square inch). As far as the manufacturer's directions are carefully observed, the amalgams sold on the market today are proven to have sufficient strength and, therefore, clinical failures of the amalgam should be sought in its inherent features of low tensile and shearing strengths rather than in the compressive strength alone.

The majority of researches connected with the amalgam have been concerned with its physical properties such as compressive strength, flow and dimensional change but studies on the tensile strength, an important property of the amalgam from the clinical point of view, are relatively scanty $[1,20,21,22,23,24,25,26]$. The tensile strength of the amalgam was given by TAYLOR [1] to be about $1 / 10$ of the compressive strength, while a study by RODRIGUEZ and Dickson [25] found it to be $1 / 4$ to $1 / 5$.

As previously stated, the spherical amalgam as an improvement on the conventional amalgam in existence is proven to be excellent in many aspects, physical and clinical. In the present study, the authors concerned themselves with a comparative examination between the spherical and conventional amalgams relative to the tensile strength, elongation and modulus of elasticity.

\section{Materials and Methods}

\subsection{Materials.}

By way of experimental materials, use was made of 2 spherical amalgam alloys of Japanese-made and 2 domestic and 1 foreign conventional amalgam alloys as control, as given in Table 1. 
TABLE 1

Alloys Tested

\begin{tabular}{c|c|c|c}
\hline \hline Abbreviation & \multicolumn{1}{|c|}{ Alloy } & Batch No. & \multicolumn{1}{c}{ Manufacturer } \\
\cline { 2 - 4 } S & Shofu Spherical non-zinc & 67 & Shofu Mfg. Co. \\
\hline A & Luna Atomic & C. S. 19 & G. C. Chemical \\
\hline M & Micro non-zinc & 43 & Shofu Mfg. Co. \\
\hline L & Luna & R. S. 19 & G. C. Chemical \\
\hline N & New True Dentalloy & $1,246,606$ & S. S. White
\end{tabular}

\subsection{Determination of specimen size.}

As described in Chapter 1 Introduction, published literature on the tensile strength of the amalgam is scanty and when we look for any detailed study on the subject, it is more limited. The size of test specimens used by the previous investigaters is of three kinds as is given in Table 2.

Prior to the present study, the authors had examined the justification of the size of test specimens used by these workers. In terms of the volumetric size, test specimens used by WARD [20] and TAYLOR[1] were quite large. As TAYLOR mentioned himself, test specimens of his size were difficult concerning the trituration and con-

TABLE 2

Various Sizes of Test Specimens

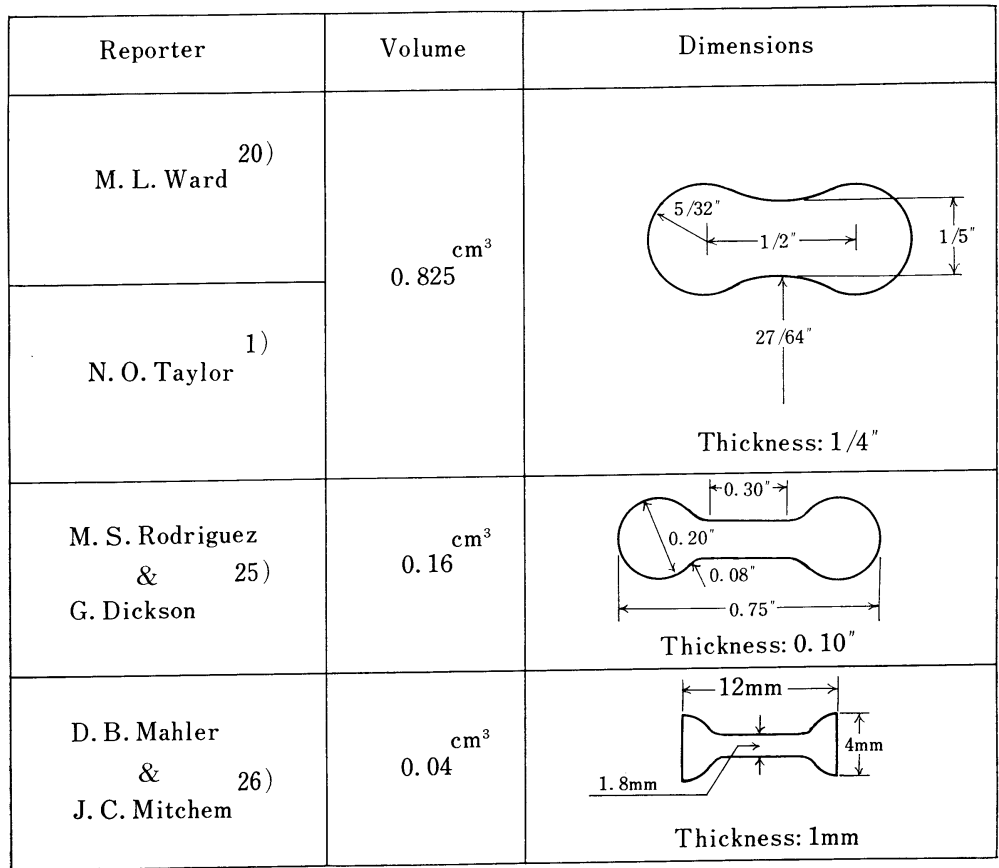


densation and he thought that these of smaller size would be more suitable.

The test specimen of this size was considered improper for the purpose of our study in that our objective also included the elongation and modulus of elasticity of the amalgam.

As for the test specimens used by RODRIGUEZ [25], who condensed specimens into the metal mold as they were, and that by MAHLER [26], packed and molded in a $1 \mathrm{~mm}$ metal mold vertically, we found the former to be much better for the purpose of grasping the specimen more accurately at the time of testing.

For this reason, we decided to adopt the size of test specimens used by RoDRIGUEZ. Here the inch system was converted into the metric one (Fig. 1).

\subsection{Preparation of test specimens.}

In preparing our test specimens, an alloy-mercury ratio was decided on $1.0: 0.85$ for the spherical amalgam and that for the conventional amalgam was $1.0: 1.4$, the constituent elements being weighed by the scales with a precision of $0.01 \mathrm{~g}$. The trituration was effected by the use of G-C Amalgamator Luna II-B for 15 seconds. Of the spherical amalgams, G-C Luna Atomic was quite rapid in its setting and, for this reason, it was triturated in two increments for 5 seconds each.

Fig. 2 shows the parts of metal mold and its assembly used for our test specimens. The amalgam mix thus triturated was formed in a strip in a sheet of powder paper and divided into 4 equal parts. To begin with, one-fourth part was inserted

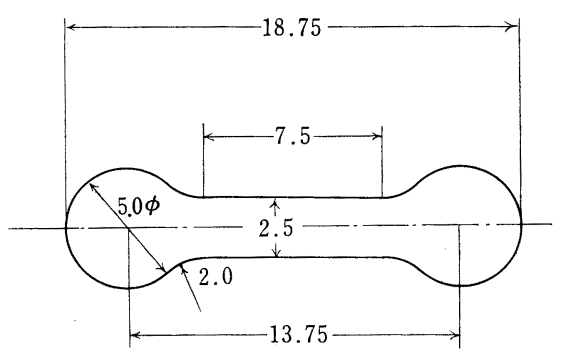

Thickness: 2.5 (Unit: $\mathrm{mm}$ )

Fig. 1. Dimensions of test specimen.

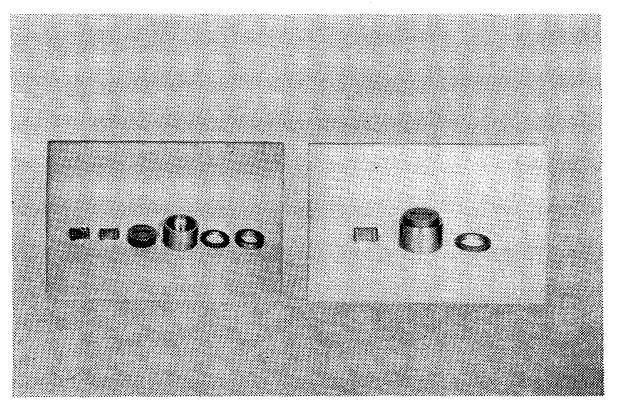

Fig. 2. Metal mold for preparing test specimens.

into the metal mold which was placed on a platform scale and was routinely packed, under a load of $1.5 \mathrm{~kg}\left(30 \mathrm{~kg} / \mathrm{cm}^{2}\right)$, to a uniform thickness by means of a manual condenser with $2.5 \mathrm{~mm}$ diameter. The remaining three parts were similarly condensed. Finally, a core having the identical dimension as test specimens was inserted and a load of $18.6 \mathrm{~kg}\left(30 \mathrm{~kg} / \mathrm{cm}^{2}\right)$ was applied for 60 seconds. All the procedures were completed in 6 minutes after the start of mixing including the time for final load.

After the final load was removed, a sharp edge was applied to the upper part of the mold and cut off an excessive part, then the test specimen was pushed out. The amount of mercury removed at the time of final load was collected and weighed so as to compute the amount of residual mercury. Although the amount of mercury obtained in this way did not represent residual mercury in an exact measure, it was adopted as a working indicator for the sake of convenience.

Preparation, subsequent storage of these test specimens and performance of experi- 
ments were done under room temperature of $23 \pm 2^{\circ} \mathrm{C}$.

\subsection{Testing apparatus.}

The testing apparatus used was Micro Universal Testing Machine manufactured by Shimazu Seisakusho, Ltd., Japan, its outlines given in Fig. 3.

As indicated in Fig. 4, it is constructed in such a way that a test specimen ( $\mathbf{S}$ ) is placed between the chucks $\left(\mathbf{C}_{1}\right.$ and $\left.\mathbf{C}_{2}\right)$ and the tracting rod $(\mathbf{R})$ moves in the direction of an arrow and gives a tensile stress to the test specimen, and its speed is controlled changing the revolution of motor $(\mathbf{M})$ and gear $(\mathbf{G})$ ratio. On the other hand, the chuck $\left(\mathbf{C}_{2}\right)$ is equipped with the measurement spring (Ms), which receives strain to be generated proportionally to the amount of stress on the part of test specimen. The amount of strain of (Ms) is reflected on a concave mirror (Me) installed on the tripod $(\mathbf{T})$ in terms of vertical inclination in proportion to a load involved. An elongation of a test specimen then will be indicated on the concave mirror (Me) in terms of horizontal inclination. Light coming from the source $(\mathbf{P})$ focuses itself on a sensitivity

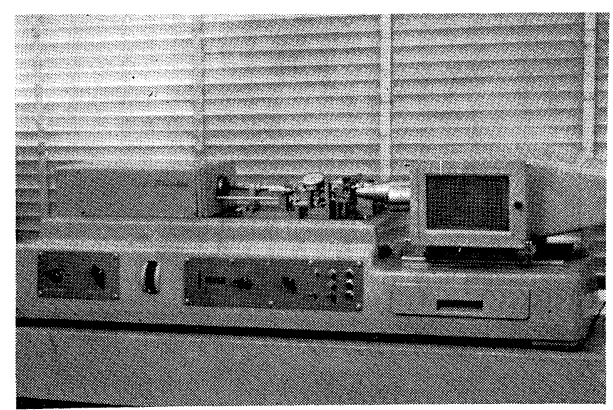

Fig. 3. Micro Universal Testing Machine (outside view).

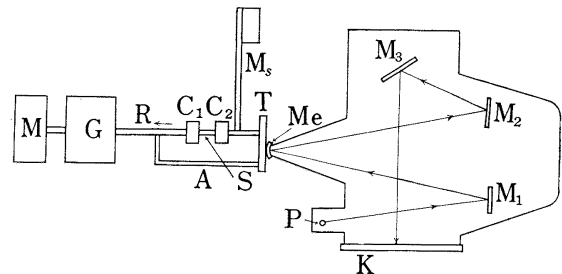

$\mathrm{M}$ : Motor; $\mathrm{Me}$ : Concave mirror; $\mathrm{G}$ : Speed controlling gear; $\mathrm{T}$ : Tripod; $\mathrm{R}$ : Tracting rod; $\mathrm{P}$ : Light source; $\mathrm{C}_{1}, \mathrm{C}_{2}$ : Chuck; $\mathrm{M}_{1}, \mathrm{M}_{2}, \mathrm{M}_{3}$ : Reflecting mirror; Ms : Measuring spring; $\mathrm{K}$ : Screen; $\mathrm{S}$ : Test specimen; A : Tripod support

Fig. 4. Schematic illustration of Micro Universal Testing Machine.

plate $(\mathbf{K})$, having been through the plane mirror $\left(\mathbf{M}_{1}\right)$, concave mirror $(\mathbf{M e})$ and two other plane mirrors $\left(\mathbf{M}_{2}, \mathbf{M}_{3}\right)$. Since the concave mirror $(\mathbf{M e})$ inclines proportionally to a load involved, the light moves along and the sensitivity plate records a load in terms of the ordinate and an elongation in the abscissa.

For purposes of the bending and shearing tests, the same procedures could be repeated by changing respective attachments. The readings were recorded, as was the case with the tensile strength, in terms of the ordinates and abcissas. The cross head speed could be successively changed from 0.5 to $125 \mathrm{~mm}$ per minute and a load could vary from $20 \mathrm{~g}$ to $100 \mathrm{~kg}$ by the exchange of measurement springs.

In passing, it may be mentioned that the holders attached to our testing apparatus were suitable for metal pieces such as gold and nickel-chromium alloys and were not fit for a brittle material like the amalgam. For this reason, special effort was made to improve on the holders by the introduction of universal bearings, so that they would exert only a tensile stress on the test specimens (Fig. 5).

These universal bearings were used in areas $(\mathbf{A})$ and $(\mathbf{B})$ of the figure, and the bearing at (B) had an opening for a test specimen to be inserted. Brass stand (C) was placed beneath the bearing $(\mathbf{B})$ held by a fixture $(\mathbf{D})$, so that the test specimen 
could be kept at a level plane at testing. By the use of this brass stand, a tensile stress to be exerted on the specimen was made to be applied on the center of it.

\subsection{Testing method.}

Immediately before testing was undertaken, the central portion of a test specimen was measured by a $0.001 \mathrm{~mm}$ micrometer concerning its width and thickness and when it was placed on the Micro Universal Testing Machine as in Fig. 6, in conjunction with $100 \mathrm{~kg}$ measurement spring, a load was so increased as to fracture it at a speed of $0.5 \mathrm{~mm}$ per minute. At fracture, the measurement was read by the sensitivity plate.

As was tried by RODRIGUEZ et al. [25], the gauge length which extended beyond the straight portion of the specimen was also selected here for convenience in marking the specimen and in measuring the change in length. Since it is usual practice to measure an elongation in a portion parallel to both sides, the length of the straight portion was made as $7.0 \mathrm{~mm}$ and, by the use of a comparator with a precision of $0.001 \mathrm{~mm}$, this distance was subjected to the measurement both before and after testing.

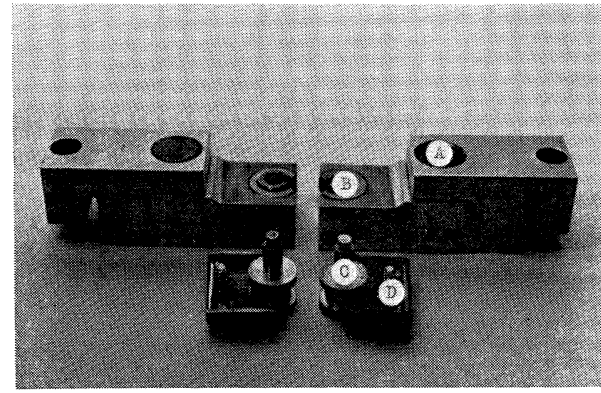

Fig. 5. Holders for test specimens.

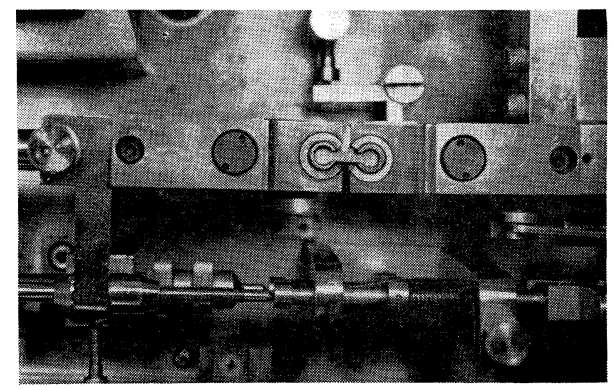

Fig. 6. Enlarged view of a specimen being tested.

That part of the measurement which registered an increase was subtracted from the original length and was expressed as a percentage elongation. In order to insure accuracy of the data, care was taken to hold the fractured pieces as tightly as possible and the measurement was made by arranging them in a staight line as much as possible.

Although a load-elongation curve was portrayed on the sensitivity plate, it included not only the strain of the amalgam but also chucks, so it was impossible to obtain

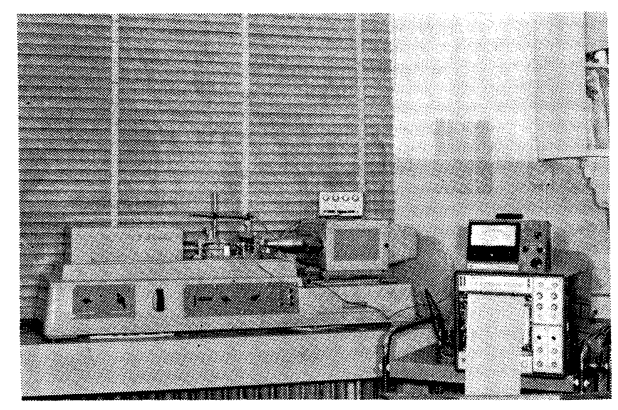

Fig. 7. Device for recording the stress-strain curve. accurate data. To avoid this, electric strain gages were attached on the upper and the lower sides of the straight portion of the specimen, and the load was electrically converted by a differential transformer, strain and load being recorded on the X-Y recorder (Fig. 7). Stress-strain curves were subsequently computed from them. Strain gages used in the study were Foil Strain Gage made by Shinko Telecommunication Co., $4 \times 2 \mathrm{~mm}$, gage resistance $120.0 \Omega \pm 1 \%$, gage factor 2.19 , lot no. 1141. These were attached on 
the test specimen by means of Aron Alpha (alpha cyanoacrylate), product by Toa Synthetic Chemicals, Ltd. By attaching the strain gages in a parallel manner, it was confirmed that it was possible to record elongation of the specimen without being interfered by bending.

An X-Y recorder used was that of AS-11 Type also by Shinko Telecommunication Co., and the calibration of load was conducted before test on the chart of the $\mathrm{X}-\mathrm{Y}$ recorder

The specimens which broke down in the straight portion were alone selected for data computation. Means were adopted on a sample of 5 to 10 test specimens.

\section{Results}

\subsection{Tensile strength.}

Respective tensile strengths of the amalgams tested are given in Table 3 and Figs. 8 and 9. Fig. 8 gives changes in the tensile strength till 24 hours, while Fig. 9 relates to these till 90 days.

As is shown by the curves in Fig. 8, 2 spherical amalgams gave far better tensile strength than any of 3 other conventional amalgams. The tensile strengths were in the order of Shofu spherical, G-C atomic, New True Dentalloy, Micro Non-zinc and G-C Luna. Fig. 9 also supports the advantage of spherical amalgam than conventional amalgam in this respect. The curves here gather themselves into two distinct groups: the upper curve relates to spherical while the lower curve indicates conventional amal-

TABLE 3

Effect of Age on Tensile Strength of Spherical and Conventional Amalgams

\begin{tabular}{|c|c|c|c|c|c|}
\hline \multirow[b]{2}{*}{ Age } & \multicolumn{2}{|c|}{ Spherical } & \multicolumn{3}{|c|}{ Conventional } \\
\hline & Shofu & Atomic & Micro & Luna & $\begin{array}{l}\text { New True } \\
\text { Dentalloy }\end{array}$ \\
\hline 1 hour & $136 \stackrel{\mathrm{kg} / \mathrm{cm}^{2}}{(20)}$ & $144 \stackrel{\mathrm{kg} / \mathrm{cm}^{2}}{(24)}$ & $69 \stackrel{\mathrm{kg} / \mathrm{cm}^{2}}{7)}$ & $59 \stackrel{\mathrm{kg} / \mathrm{cm}^{2}}{(15)}$ & $89 \stackrel{\mathrm{kg} / \mathrm{cm}^{2}}{(16)}$ \\
\hline 3 hours & 216 & $184(9)$ & $107(8)$ & 109 (19) & 179 \\
\hline 6 hours & $297(72)$ & 276 & $146(26)$ & $132(24)$ & $228(30)$ \\
\hline 12 hours & $452(71)$ & $426 \quad(53)$ & $338 \quad(57)$ & $182(24)$ & $395(57)$ \\
\hline 1 day & $531 \quad(79)$ & $493(61)$ & $451 \quad(52)$ & $365(64)$ & $473 \quad(54)$ \\
\hline 3 days & $556(100)$ & $516 \quad(84)$ & $462 \quad(69)$ & $448 \quad(52)$ & $552(57)$ \\
\hline 7 days & $566(86)$ & 549 & $472(39)$ & $438 \quad(53)$ & $534(96)$ \\
\hline 14 days & 574 & $536(57)$ & $451 \quad(90)$ & $448 \quad(92)$ & $552(73)$ \\
\hline 30 days & $557(87)$ & 550 & $467 \quad(31)$ & $442 \quad(22)$ & $541 \quad(68)$ \\
\hline 90 days & $581(60)$ & $568(64)$ & $478 \quad(37)$ & $455(60)$ & $554(76)$ \\
\hline $\begin{array}{l}\text { Residual Hg. } \\
\text { percentage }\end{array}$ & $45.1 \%$ & $44.9 \%$ & $54.1 \%$ & $55.2 \%$ & $49.0 \%$ \\
\hline
\end{tabular}

Numbers in parentheses indicate standard deviation. 


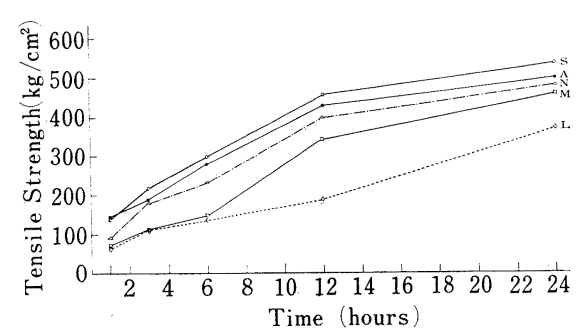

Fig. 8. Effect of age on tensile strength of spherical and conventional amalgams.

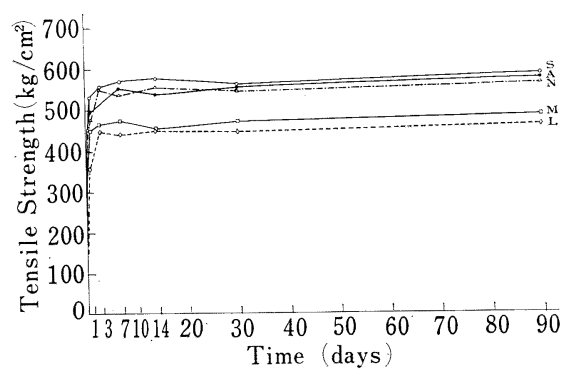

Fig. 9. Effect of age on tensile strength of spherical and conventional amalgams.

gams. Of conventional amalgams, however, New True Dentalloy belongs to the upper curve. In long-term observations, a pronounced increase in the tensile strength occurred by 24 hours but the strength did not register any further change after the passage of 3 days.

\subsection{Elongation.}

Results of our elongation test on the spherical and conventional amalgams in 7 days are given in Table 4. As shown, two sets of data are fairly low with a range of 0.10 to $0.16 \%$. Two spherical amalgam products gave $0.10 \%$ alike and conventional

TABLE 4

Elongation of Dental Amalgam

7 day-old specimens.

\begin{tabular}{l|cc}
\hline \multicolumn{1}{c|}{ Alloy } & \multicolumn{2}{c}{ Elongation (\%) } \\
\hline Shofu Spherical & $0.10 \quad(0.05)$ \\
\hline Atomic & $0.10 \quad(0.03)$ \\
\hline Micro Non-zinc & $0.13 \quad(0.04)$ \\
\hline Luna & $0.11 \quad(0.05)$ \\
\hline New True Dentalloy & $0.16 \quad(0.07)$
\end{tabular}

Numbers in parentheses indicate standard deviation.

amalgams gave an average elongation of $0.11-0.16 \%$. Therefore, there was not observed any significant difference between spherical and conventional amalgams.

\subsection{Stress-strain curve and modulus of elasticity.}

RODRIGUEZ et al. [25] measured the strain by using optical strain gages until a load of $28 \mathrm{~kg}$ was reached. In the present study, the authors were able by the use of a electric strain gages and a differential transformer to measure stress-strain curves till the fracture took place in test specimens.

Fig. 10 gives some representative stress-strain curves of various amalgams tested. As 


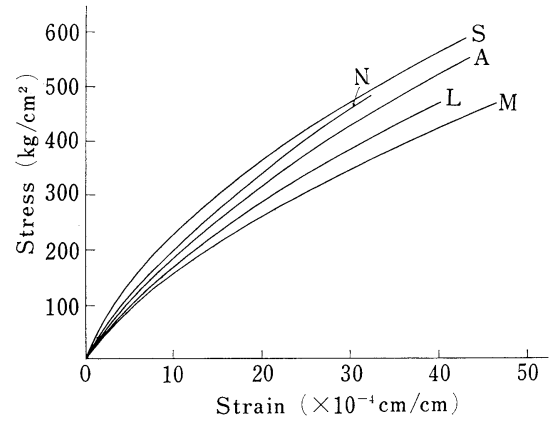

Fig. 10. Typical stress-strain curves.

is shown by the figure, there is observed no straight line which determines proportional limit or modulus of elasticity so familiar with the strength of materials. For this reason, use is made of the so-called chord modulus by linking two points of 50 and 150, 50 and $300 \mathrm{~kg} / \mathrm{cm}^{2}, 2$ points in the stress-strain curve diagram here, to obtain the moduli of elasticity. After the passage of 7 days, the moduli of elasticity of amalgam were $29 \times 10^{4}-37 \times$ $10^{4} \mathrm{~kg} / \mathrm{cm}^{2}$ (within a stress range of $50-150$ $\mathrm{kg} / \mathrm{cm}^{2}$ ) and $22 \times 10^{4}-30 \times 10^{4} \mathrm{~kg} / \mathrm{cm}^{2}$ (within a stress range of $50-300 \mathrm{~kg} / \mathrm{cm}^{2}$ ) respectively, as given in Table 5 .

TABLE 5

Chord Moduli of Elasticity of Dental Amalgam

7 day-old specimens

\begin{tabular}{|c|c|c|}
\hline \multirow{2}{*}{ Alloy } & \multicolumn{2}{|c|}{ Stress range } \\
\hline & $50-150 \mathrm{~kg} / \mathrm{cm}^{2}$ & $50-300 \mathrm{~kg} / \mathrm{cm}^{2}$ \\
\hline Shofu Spherical & $35 \stackrel{\times 10^{4} \mathrm{~kg} / \mathrm{cm}^{2}}{(8.0)}$ & $30 \stackrel{\times 10^{4} \mathrm{~kg} / \mathrm{cm}^{2}}{(4.2)}$ \\
\hline Atomic & $35 \quad(3.4)$ & $29 \quad(2.3)$ \\
\hline Micro & $29 \quad(3.6)$ & $22 \quad(2.3)$ \\
\hline Luna & $29 \quad(4.3)$ & $25 \quad(4.1)$ \\
\hline New True Dentalloy & $37 \quad(2.1)$ & $30 \quad(2.0)$ \\
\hline
\end{tabular}

Numbers in parentheses indicate standard deviation.

\section{Discussion}

In his work on the tensile test on amalgam, WARD [20] reported that they developed fracture under an average load of $127 \mathrm{~kg}$ (280 pounds). Although the age of his specimens is not clear, we can construct from his specimen size in Table 2 that it corresponds to about $390 \mathrm{~kg} / \mathrm{cm}^{2}$ by way of the tensile strength. TAYLOR [1], who used the same size test specimens as Ward, measured the tensile strength of various amalgams and gave $203-420 \mathrm{~kg} / \mathrm{cm}^{2}(2900-6000 \mathrm{psi})$ to be the strength after 5 days.

RODRIGUEZ and DiCKSON [25] obtained the tensile strength of 4 different amalgams on a chronological basis and gave $49-78 \mathrm{~kg} / \mathrm{cm}^{2} \quad(700-1100 \mathrm{psi}), 410-530 \mathrm{~kg} / \mathrm{cm}^{2}(5800-$ $7500 \mathrm{psi})$ and $490-590 \mathrm{~kg} / \mathrm{cm}^{2}(7000-8400 \mathrm{psi})$ as the respective tensile strengths after 1 hour, 1 day and 7 days.

Our own data here were $59-89 \mathrm{~kg} / \mathrm{cm}^{2}$ (1 hour), $365-473 \mathrm{~kg} / \mathrm{cm}^{2}$ (1 day) and 438$534 \mathrm{~kg} / \mathrm{cm}^{2}$ (7 days). They are in keeping with the findings of RODRIGUEz. When the tensile strength of spherical amalgam is compared with that of conventional amalgam 
in the parallel portion where the setting had been completed, 2 spherical amalgams tested give the same degree of tensile strength as New True Dentalloy, which gives the highest tensile strength among conventional amalgams. In the initial strength, however, spherical amalgam has proven itself much stronger. That is, after the passage of one hour the tensile strength of spherical amalgam is $136-144 \mathrm{~kg} / \mathrm{cm}^{2}$, while that of conventional amalgam is $59-89 \mathrm{~kg} / \mathrm{cm}^{2}$, the former being nearly twice as much as the latter. The tensile strength after one hour of conventional amalgam is 13 to $17 \%$ of what it would be after one week (it corresponds to 10 to $15 \%$ given by RoDRIGUEZ), while spherical amalgam has 24 to $26 \%$ of 1 -week tensile strength. In other words, the tensile strength of spherical amalgam after 1 hour corresponds to nearly $1 / 4$ of what it would be after 1 week, while that of conventional amalgam is only $1 / 6$ to $1 / 8$.

This fact is in keeping with the findings by NAGAI, OHASHI and MIYAZU [9] that the spherical amalgam has much stronger compressive strength in the initial setting phase. The present study confirms the fact that the spherical amalgam is more advan. tageous than the conventional amalgam not only in compressive, but also in tensile strengths.

Table 6 compares the compressive and tensile strengths of both spherical and conventional amalgams. The tensile strength in general is much smaller than the compressive strength, corresponding to only $1 / 6.3$ to $1 / 6.6$. There seems to be no appreciable differences between the two amalgams in this respect. As for the difference between the two strengths, TAYLOR [1] gave nearly 1/10 and RODRIGUEZ et al. [25] $1 / 4$ to $1 / 5$. Our result is more in agreement with that of the latter. A work by

TABLE 6

Comparison of Tensile and Compressive Strength of the Amalgam

$30 \mathrm{~kg} / \mathrm{cm}^{2}$ condensation, 24 hour old specimens

\begin{tabular}{l|c|c}
\hline \multirow{2}{*}{\begin{tabular}{c} 
Strength \\
\cline { 2 - 3 }
\end{tabular}} & Shofu Spherical & Alloy \\
\cline { 2 - 3 } & $1.0: 0.85$ & Shofu Micro \\
\hline Tensile & $531 \quad \mathrm{~kg} / \mathrm{cm}^{2}$ & $1.0: 1.4$ \\
\hline Compressive* & $3,328 \mathrm{~kg} / \mathrm{cm}^{2}$ & $451 \mathrm{~kg} / \mathrm{cm}^{2}$ \\
\hline Compressive-tensile ratio & 6.3 & $2,991 \mathrm{~kg} / \mathrm{cm}^{2}$ \\
\hline
\end{tabular}

* Data are cited from Dr. Nagai et al. (Ref. 9).

RODRIGUEZ et al. appears to be the only one so far which deals with the elongation and modulus of elasticity of the amalgam. To measure the elongation, we marked reference lines within the straight portion of the specimen, but they did near the middle of the round portion. For this reason, it was originally supposed to come up with larger measurement than these workers but, as a matter of fact, our actual measurement of an elongation was merely 0.10 to $0.16 \%$, which corresponds to less than one-half of 0.3 to $0.5 \%$ given by RODRIGUEz. The difference here may be accounted for by the fact that fractured amalgam pieces between the two measurement points had to be collected and arranged in a straight line for the purpose of measuring it. The collection ond arrangement of pieces will present no problem with a material of elastic nature but 
there is experienced certain difficulty with a brittle material such as the amalgam.

The authors tried to collect and arrange the fractured pieces in a straight line as much as possible and measured change in the length in a central position. Whatever the reason, our measurement did not come near that of RODRIGUEZ et al.

As regards an elongation, there is no significant change between spherical $(0.10$ $\%)$ and conventional amalgams $(0.11-0.16 \%)$. The moduli of elasticity of spherical and conventional amalgams are compared in Table 5 .

As is learned from the comparison, two spherical amalgams tested have the same modulus of elasticity as New True Dentalloy, which have a higher modulus of elasticity among the conventional amalgams.

The moduli of elasticity obtained in our tests are found to be somewhat larger than those obtained by RODRIGUEz.

In this connection, it was reported by RODRIGUEZ et al. that though the head speed had no appreciable influence on the tensile strength, a greater head speed resulted in a larger modulus of elasticity in a series of preliminary tests [25].

In our study here, the minimum head speed was $0.5 \mathrm{~mm}$ per minutes but as a strain of the measurement spring had certain effect on the speed, an actual speed of load on the test specimen was somewhat reduced. It is reasonable to infer that since our head speed was greater than that used by RODRIGUEZ et al. whose speed was $0.0762 \mathrm{~mm}$ per minute $(0.003 \mathrm{in} . / \mathrm{min}$.), our data became correspondingly large.

A comparison of the moduli of elasticity of dentin and various filling materials is given in Table 7. As is known from this, the modulus of elasticity of the amalgam is not different from those of human dentin and silicate cement, on the one hand, but widely varies from filling resins, on the other. When the tensile strength (Table 3) is comparatively examined with the modulus of elasticity (Table 5), the amalgam which has a greater tensile strength tends to have a correspondingly large modulus of elasticity.

TABLE 7

Comparison of moduli of elasticity in tension of some filling materials and dentin

\begin{tabular}{l|c|c}
\hline \multirow{2}{*}{ Material } & \multicolumn{1}{|c}{ Modulus of elasticity } \\
\cline { 2 - 2 } & $\times 10^{6} \mathrm{psi}$ & $\times 10^{4} \mathrm{~kg} / \mathrm{cm}^{2}$ \\
\hline Human dentin & $2.8^{*}$ & 20 \\
\hline A silicate cement & $3.1^{*}$ & 22 \\
\hline A direct filling resin & $0.26^{*}$ & 1.8 \\
\hline Amalgam & $2.2 \sim 2.8^{* *}$ & $16 \sim 20$ \\
\hline Amalgam & & $22 \sim 30$ \\
$* \quad \begin{array}{l}\text { Data from Bowen and Rodriguez (Ref. 27). } \\
\text { Data from Rodriguez and Dickson (Ref. 25). }\end{array}$
\end{tabular}

\section{Conclusions}

As a result of the foregoing comparative study of the tensile strengths, elongations and moduli of elasticity on 2 spherical and 3 conventional amalgams, the authors 
reached the following conclusions.

1. The tensile strength of spherical amalgam, in its initial phase in particular, is much better than conventional amalgam. The tensile strength after 1 hour of the former corresponds to nearly twice as much as the latter. Whereas the tensile strength of spherical amalgam after 1 hours agrees with $1 / 4$ of what it will be after 1 week, that of conventional amalgam merely corresponds to $1 / 6$ to $1 / 8$ after the same passage of time.

2. Actual measurements of the tensile strength after 1 week were $549-566 \mathrm{~kg} / \mathrm{cm}^{2}$ for spherical and $438-534 \mathrm{~kg} / \mathrm{cm}^{2}$ for conventional amalgams respectively. Thus, the tensile strength of spherical amalgam agrees with a type of conventional amalgams that possesses the highest degree of tensile strength.

3. Although a compressive-tensile strength ratio is about 6.5 , difference between the spherical and conventional amalgams in this respect is not appreciable.

4. Amalgam has a low percentage elongation, approximately 0.10 to $0.16 \%$. In this respect, there is observed no appreciable difference between the two amalgams.

5. The chord modulus of elasticity of amalgam is $29 \times 10^{4}-37 \times 10^{4} \mathrm{~kg} / \mathrm{cm}^{2}$ in a stress range of $50-150 \mathrm{~kg} / \mathrm{cm}^{2}$ and is $22 \times 10^{4}-30 \times 10^{4} \mathrm{~kg} / \mathrm{cm}^{2}$ in a stress range of $50-300$ $\mathrm{kg} / \mathrm{cm}^{2}$.

The spherical amalgam belongs to a class of larger modulus of elasticity.

6. On the whole, the amalgam which has a large tensile strength is found to have a correspondingly large modulus of elasticity.

\section{References}

[1] TAYLOR, N. O. : A specification for dental amalgam alloys: A report to the Scientific Foundation and Research Commission of the American Dental Association, J. Amer. dent. Assoc. $17:$ 112-124, 1930.

[2] Amer. Dent. Assoc. Bureau of Economic Research and Statistics: 1959 survey of dental practice, J. Amer. dent. Assoc., 62: 627-636, 1961.

[ 3 ] Healey, H. J. and Phillips, R. W. : Clinical study of amalgam failure, J. dent. Res., $28: 439-446,1949$.

[4] Seino, S. : Clinical observations on the amalgam fillings in school children as an early precaution against the dental caries, J. Japan Research Soc. dent. Mat. and Appl., 15: 25-33, 1966.

[ 5 ] Fusayama, T., Wakumoto, S., Katayori, T., Kono, A., Shimizu, M., Hanari, M. and HAYASHI, K. : Clinical results of amalgam fillings, J. Japan Research Soc. dent. Mat. and Appl., 8: 77-88, 1962.

[6] Saijo, M. : On the prognosis of amalgam fillings, Shikai-Tenbo, 15: 794-798, 1958.

[7] Habu, H., Henmi, I. and Kunit, H. : Failures in amalgam restoration, J. Japan Research Soc. dent. Mat. and Appl., 6: 32-36, 1961.

[8] Wilson, C. J. and Ryge, G. : Clinical study of dental amalgam, J. Amer. dent. Assoc., $66: 763-771,1963$.

[9 ] Nagai, K., Ohashi, M. and Mryazu, H. : Studies on spherical amalgam alloy in the light of dental technology, J. Nihon Univ. Sch. Dent., 8: 149-185, 1966.

[10] Probst, R. L., Karp, P. I., Sayre, C. H. and Beebe, A. H. Jr. : Assignors to Federal Mogul-Bower Bearings, Inc., Detroit, Michigan. Atomizing nozzle and pouring cap assembly for the manufacture of metal powders. U. S. Patent No. 2,968,092, January 17, 1961.

[11] Demaree, N. C. and Taylor, D. F. : Properties of dental amalgams made from spherical alloy particles, J. dent. Res., 41: 890-906, 1962. 
[12] KORAn, A. and ASGAR, K. : Usage of spherical amalgam alloy in dentistry, presented at the Int. Assoc. dent. Res. annual meeting. Toronto, Canada, July, 1965.

[13] Eden, G. T. and Waterstrat, R. M. : Effect of packing pressure on tensile strength of commercial and spherical dental amalgams, presented at the Int. Assoc. dent. Res. annual meeting, Toronto, Canada, July, 1965.

[14] Wing, G. and RYGE, G. : Setting reactions of spherical-particle amalgams, J. dent. Res., 44 : 1325-1333, 1965.

[15] Nagai, K. and OHashi, M. : Studies on the dimensional change of dental amalgams, - with reference to the dimensional change of spherical amalgam developed in Japan-, J. Nihon Univ. Sch. Dent., 9 : 1-19, 1967

[16] NagAi, K. and OHAshi, M. : Three studies on a newly developed spherical amalgam in Japan and suggestions for its specification, J. Nihon Univ. Sch. Dent., 9: 43-48, 1967.

[17] Nagai, K., Ohashi, M. and Hasegawa, K. : Comparative study on the marginal strengths of conventional and spherical amalgam alloys, J. Nihon Univ. Sch. Dent., 9 : 49-66, 1967.

[18] Nagai, K and Ohashi, M. : Study on the corrosion resistancy of spherical amalgam with reference to the human saliva, J. Nihon Univ. Sch. Dent., 9: 143-163, 1967.

[19] Skinner, E. W. and Phillips, R. W. : The science of dental materials, W. B. Sauders Company, Philadelphia, 6th. ed. 1967.

[20] WARD, M. L. : Modern tests for the strength of amalgam, J. Amer. dent. Assoc., 11 : 487-496, 1924.

[21] Coy, H. D. and LifBig, E. O. : Dental amalgam, Dent. Items Int., 60 : 142, 1938.

[22] Mahler, D. B. : An analysis of stresses in a dental amalgam restoration, J. dent., Res. $37: 516-526,1958$.

[23] Mahler, D. B. and Terkla, L. G. : Analysis of stress in dental structures, Dent. Clin. North America. 789-798, 1958.

[24] SwEENEy, J. T. : Uncontrolled variables in amalgam, with significant improvements in the making of restorations, J. Amer. dent. Assoc., 27 : 190-197, 1940.

[25] Rodriguez, M. S. and Dickson, G. : Some tensile properties of amalgam, J. dent. Res., 41 : 840-852, 1961.

[26] Mahler, D. B. and Mitchem, J. C. : Transverse strength of amalgam, J. dent. Res., 43 : 121-130, 1964.

[27] Bowen, R. L. and Rodriguez, M. S. : Tensile strength and modulus of elasticity of tooth structure and several restorative materials, J. Amer. dent. Assoc., 64: 378-387, 1962. 